\title{
Delayed memory for visual-haptic exploration of familiar objects
}

\author{
Allison E. C. Pensky, Kathryn A. Johnson, Susan HaAg, and Donald Homa \\ Arizona State University, Tempe, Arizona
}

\begin{abstract}
Long-term memory of haptic, visual, and cross-modality information was investigated. In Experiment 1, subjects briefly explored 40 commonplace objects visually or haptically and then received a recognition test with categorically similar foils in the same or the alternative modality both immediately and after 1 week. Recognition was best for visual input and test, with haptic memory still apparent after a week's delay. Recognition was poorest in the cross-modality conditions, with performance on the haptic-visual and visual-haptic cross-modal conditions being nearly identical. Visual and haptic information decayed at similar rates across a week delay. In Experiment 2, subjects simultaneously viewed and handled the same objects, and transfer was tested in a successive cue-modality paradigm. Performance with the visual modality again exceeded that with the haptic modality. Furthermore, initial errors on the haptic test were often corrected when followed by the visual presentation, both immediately and after 1 week. However, visual test errors were corrected by haptic cuing on the immediate test only. These results are discussed in terms of shared information between the haptic and visual modalities, and the ease of transfer between these modalities immediately and after a substantial delay.
\end{abstract}

We experience the environment through various sensory modalities working in concert. A multisensory process has behavioral advantages, including speeded response and improved recognition of novel and familiar objects in noisy contexts (Newell, 2004). Although the visual system plays the major role in sensory perception (Ernst \& Banks, 2002; James et al., 2002; Millar \& AlAttar, 2005), objects can also be recognized quickly and accurately through haptic exploration alone (Klatzky, Lederman, \& Metzger, 1985; Norman, Norman, Clayton, Lianekhammy, \& Zielke, 2004).

To what extent are the visual and haptic sensory modalities truly integrated, and to what extent are they separate? Both visual and haptic object recognition are based on the extraction of basic features and their spatial arrangement, which together define an object. However, disparate features such as context, motion, color, texture, or size, which are analyzed separately, must converge to generate such a coherent percept.

One explanation is that there are points of convergence of the parallel pathways in multimodal brain regions that integrate information from diverse modalities (Shimojo $\&$ Shams, 2001). Studies using functional magnetic resonance imaging (fMRI) indicate that the haptic system activates the visual processing system in some instances and may facilitate mental representation of objects or be part of a cross-modal network encoding information from both vision and touch (James et al., 2002).

A handful of studies have explored cross-modality transfer after short delays. Easton, Srinivas, and Greene
(1997) found that both unimodal and cross-modal accuracy rates were high for both explicit memory and implicit priming for words presented visually or in a raised format. Norman et al. (2004) demonstrated that recognition accuracy of objects for the unimodal visual condition surpassed the cross-modal conditions, suggesting that the two modalities were not necessarily equivalent in regard to detail. Bushnell and Baxt (1999) found that children, on an immediate test, demonstrated good cross-modality transfer for familiar objects but not for unfamiliar objects. Of critical importance to the present experiment, however, no studies have tested haptic or visual-haptic cross-modal memory across delays of more than $1 \mathrm{~h}$.

The present study investigated haptic, visual, and crossmodality memory immediately and after 1 week. In each experiment, the recognition test contained studied objects intermixed with foils from the same category. This guaranteed that correct recognition was based on retention of critical features rather than the category name. In Experiment 1 , subjects studied objects visually or haptically and were tested in the same or alternative modality, both immediately and after 1 week. Since the same objects were studied either visually or haptically, a comparison of same modality input and test permits a test of whether haptic information is lost more rapidly than visual information. The cross-modality contrast provides an index of how completely visual and haptic information are transferred to the other modality. In Experiment 2, subjects inspected the objects both visually and haptically and were tested on each modality in turn, either immediately or after 1 week;

D. Homa, donhoma@asu.edu 
this allowed further evaluation of the amount of shared and distinctive information.

\section{EXPERIMENT 1}

\section{Method}

Subjects. Eighty Arizona State University students (35 male and 45 female), 20 in each of the four between-subjects conditions, participated in the experiment. Three subjects were replaced, 2 for failure to understand instructions and 1 due to experimenter error. All subjects had normal or corrected-to-normal vision and none presented somatosensory deficits.

Materials and Apparatus. A cardboard "blind box" was constructed with two opaque sleeves for the haptic object study. The subject was seated at a table and inserted both arms through the sleeves so that his/her hands were free to explore objects haptically without viewing the objects. During visual presentation at study or test, an object was placed on a turntable, located about $90^{\circ}$ from the blind box. The subject was free to visually explore the object by rotating the turntable without touching the object.

The stimuli were 80 common objects found in household or office contexts, such as kitchenware, office supplies, small toys, tools, or household objects (see the Appendix). Objects made no identifying noises, emitted no special odors, and were small enough to be held comfortably in the palms of both hands. Pilot testing indicated that virtually all objects were identifiable haptically. The 80 objects were separated into two paired groups, A and B, where the objects in one set had the same categorical name as did a corresponding object in the other set. For example, sponges 4A and 4B differed only in texture and color.

Procedure. Subjects were assigned randomly to one of the four study-test conditions ( $\mathrm{V}-\mathrm{V}, \mathrm{H}-\mathrm{H}, \mathrm{H}-\mathrm{V}, \mathrm{V}-\mathrm{H})$. During the study phase, subjects were handed or shown each of 40 objects, 1 at a time. Subjects were free to handle, or rotate and view, the object for up to $15 \mathrm{sec}$ and were instructed that a memory test would follow the study phase. Each object was presented in the same position or with the same viewing angle for all subjects.

The assignment of patterns to the study and test phases, including controls, is shown in Table 1. Subjects studied the 40 objects from the A or the B list, followed by a recognition test containing 10 objects from the originally studied list and 10 randomly intermixed foils from the opposite list. Test objects were of distinct categories; that is, a test never contained a study and foil object having the same name. The delayed test was composed of the remaining 20 objects, half of which were in the study set, with the remainder being foils. Objects on both the study and test phases were presented in a random order.

At test, the subjects indicated whether an object handed or shown to them was old or new. Subjects were instructed to call an object "old" only if it matched identically an object presented during the study phase. The recognition test was self-paced, with most judgments taking less than $5 \mathrm{sec}$.

\section{Results}

Figure 1 shows the likelihood that studied objects and foils were called "old," as a function of input condition (haptic, visual), test condition (haptic, visual), and time of test (immediate, 1-week delay). The difference between hits and false alarms differed for the four conditions $\left[F(3,76)=31.61, M S_{\mathrm{e}}=2.47, p<.001, \eta^{2}=.56\right]$, with the $\mathrm{V}-\mathrm{V}$ condition exhibiting the best discrimination between hits and false alarms (.861 vs. .162). The remaining three conditions were similar in hit and false alarm rates $(\mathrm{H}-\mathrm{H}, .845$ vs. $.502 ; \mathrm{H}-\mathrm{V}, .758$ vs. $.495 ; \mathrm{V}-\mathrm{H}, .805$ vs. 485). All conditions revealed diminished ability to separate old from new objects on the delayed test relative to the immediate test, with discrimination on the delayed test
Table 1

Assignment of Objects to Study and Test Delays for Each Condition

\begin{tabular}{lcll}
\hline Subjects & Study & \multicolumn{1}{c}{ Test 1 } & \multicolumn{1}{c}{ Test 2 } \\
\hline S1-S5 & A1-A40 & $\begin{array}{l}\text { Old(A1-A10)+ } \\
\text { New(B21-B30) }\end{array}$ & Old(A11-A20)+ \\
& & New(B31-B40) \\
S6-S10 & A1-A40 & Old(A11-A20)+ & Old(A1-A10)+ \\
& & New(B31-B40) & New(B21-B30) \\
S11-S15 & B1-B40 & Old(B21-B30)+ & Old(B31-B40)+ \\
& & New(A1-A10) & New(A11-A20) \\
S16-S20 & B1-B40 & Old(B31-B40)+ & Old(B21-B30)+ \\
& & New(A11-A20) & New(A1-A10) \\
\hline
\end{tabular}

Note-A1-A40 refer to objects in the A list; B1-B40 refer to corresponding objects in the $\mathrm{B}$ list.

best for the $\mathrm{V}-\mathrm{V}$ condition (hits - false alarms $=.580$ ), worst for the $\mathrm{H}-\mathrm{V}$ condition (.150), and intermediate for the $\mathrm{H}-\mathrm{H}(.205)$ and $\mathrm{V}-\mathrm{H}(.200)$ conditions $[F(3,76)=$ 5.04, $\left.M S_{\mathrm{e}}=2.67, p<.01, \eta^{2}=.17\right]$.

Because the results in the four conditions appeared to reflect changes both in discrimination and in bias to call an object old, a signal detection analysis (Green \& Swets, 1966) was performed. Table 2 summarizes this analysis.

As expected, $d^{\prime}$ was greatest for the $\mathrm{V}-\mathrm{V}$ condition, both immediately and 1 week later $[F(3,76)=34.39$, $\left.M S_{\mathrm{e}}=0.47, p<.001, \eta^{2}=.58\right]$. The effect of delay was significant $\left[F(1,76)=83.33, M S_{\mathrm{e}}=0.36, p<.001\right.$, $\left.\eta^{2}=.52\right]$, but the condition $\times$ delay interaction was not $[F(3,76)=0.17, p>.20]$. In sum, the $\mathrm{V}-\mathrm{V}$ condition was superior to the remaining conditions (which did not differ from each other), but the rate of forgetting appeared to be similar across all four conditions. ${ }^{1}$

An analysis of bias $(c)$ revealed that the four conditions differed in terms of a criterion placement $[F(3,76)=$ 29.32, $\left.M S_{\mathrm{e}}=0.37, p<.001, \eta^{2}=.54\right]$, with the delay $\times$ condition interaction significant $\left[F(3,76)=2.82, M S_{\mathrm{e}}=\right.$ $\left.0.26, p<.05, \eta^{2}=.10\right]$. A Bonferroni subsequent test revealed that the $\mathrm{V}-\mathrm{V}$ criterion differed significantly from each of the other three conditions ( $p<.05$ in each case), but the remaining conditions did not differ from each other. The unimodal conditions showed that bias became more liberal with delay [for $\mathrm{V}-\mathrm{V}, t(19)=2.25$, and for $\mathrm{H}-\mathrm{H}, t(19)=2.04$, both $p \mathrm{~s}<.05]$. The increasing criterion across the delay for the $\mathrm{H}-\mathrm{V}$ condition fell short of significance $[t(19)=1.43, p=.17]$.

Object analysis. Table 3 shows the correlation among the condition $\times$ delay combinations for errors made to the 40 object types. On the immediate test, errors in the $\mathrm{V}-\mathrm{H}$ and $\mathrm{H}-\mathrm{V}$ cross-modality conditions were correlated $(p<.05)$, as were the errors between $\mathrm{H}-\mathrm{H}$ and each cross-

Table 2

Signal Detection Measures: Experiment 1

\begin{tabular}{cccccccrr}
\hline & \multicolumn{2}{c}{ Immediate } & & \multicolumn{2}{c}{ Week Delay } & & \multicolumn{2}{c}{ Change } \\
\cline { 2 - 3 } Condition & $d^{\prime}$ & $c$ & & $d^{\prime}$ & $c$ & & $d^{\prime}$ & \multicolumn{1}{c}{$c$} \\
\hline V-V & 2.68 & 1.18 & & 1.76 & 0.92 & & 0.92 & 0.27 \\
H-H & 1.53 & 0.18 & & 0.60 & -0.20 & & 0.93 & 0.38 \\
V-H & 1.38 & 0.09 & & 0.59 & -0.01 & & 0.79 & 0.09 \\
H-V & 1.22 & -0.11 & & 0.43 & 0.12 & & 0.79 & -0.23 \\
\hline
\end{tabular}

Note- $c$, criterion placement. 

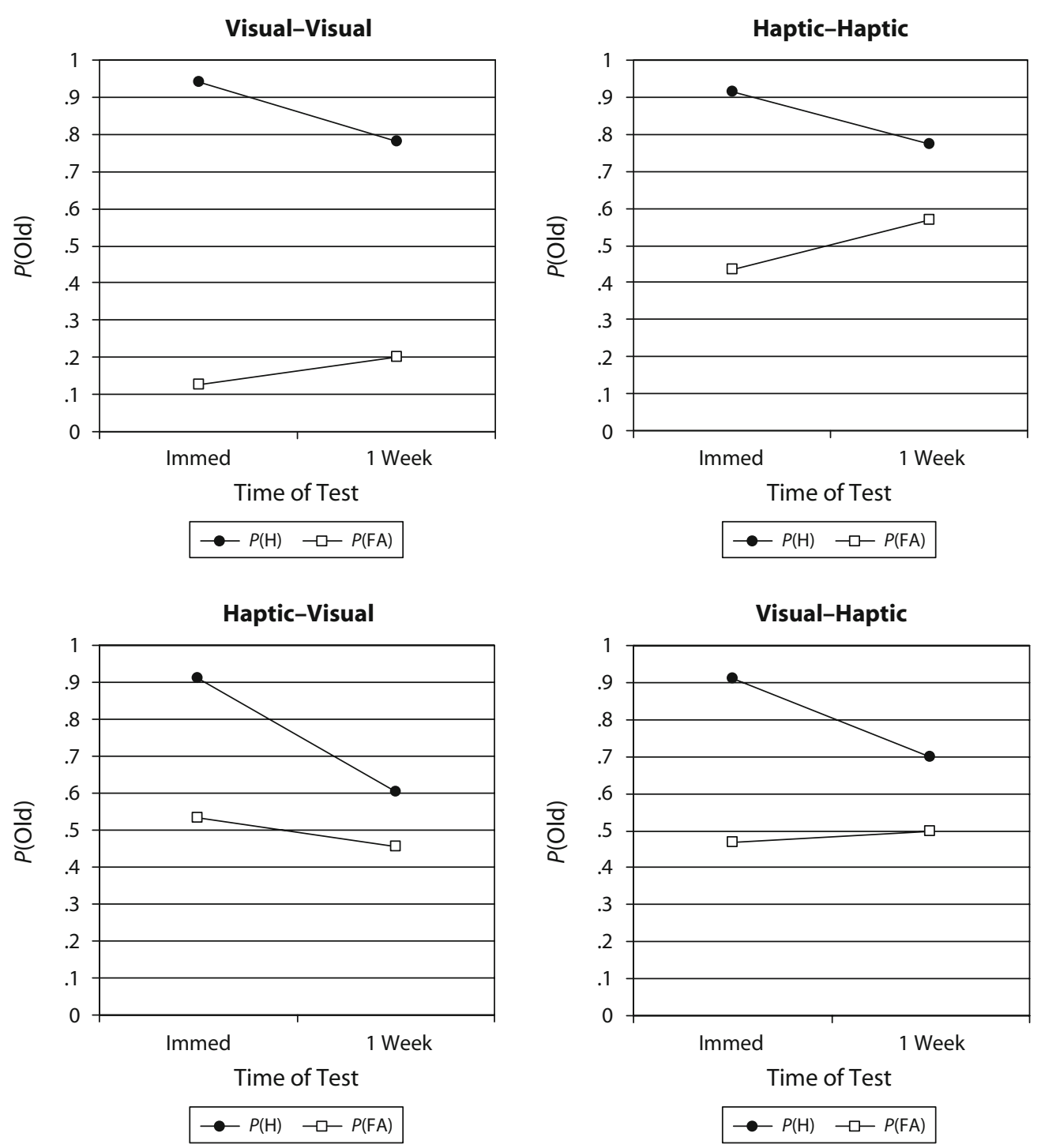

Figure 1. The likelihood of calling objects "old" on the recognition test, as a function of input condition (haptic, visual), test condition (haptic, visual), and time of test (immediate, 1-week delay).

modality condition (both $p \mathrm{~s}<.05$ ), outcomes consistent with the sharing of information between the visual and haptic modalities. The only significant correlation involving delay was for the $\mathrm{V}-\mathrm{V}$ immediate and delay condition $(p<.05)$. Inspection of individual objects revealed no obvious trend for one category to be recognized more accurately than another.

\section{Discussion}

Four results are clear: (1) Haptic memory for familiar objects, gleaned from a brief inspection, survives a week's delay; (2) memory errors on an immediate test are similar for objects studied visually or haptically; (3) considerably less information is encoded haptically than visually for the same objects at study; and (4) cross-modality transfer survives a week delay, with little performance difference between the $\mathrm{V}-\mathrm{H}$ and $\mathrm{H}-\mathrm{V}$ conditions.
A reasonable hypothesis is that more information is encoded from an object studied visually than from an object studied haptically - a safe assumption, given the results of Experiment 1 and the fact that $30 \%-50 \%$ of the cortex is devoted to visual processing (Mather, 2006) - but that these modalities share encodings. Information can be stored in any one of three ways - unique contributions from the visual and haptic modalities, and a shared part that is transferable between the haptic and visual modalities. The advantage of the visual modality arises because some encoded information, such as color, shading, and idiosyncratic details such as lettering, is not discernible from haptic exploration. The haptic modality also encodes unique details, such as texture, hardness, weight, and proprioceptive/kinesthetic properties associated with felt positions of the object. Common properties would include contour, size, and shape (Millar \& Al-Attar, 2005). 
Table 3

Correlation Between Conditions Based on Errors to the 40 Studied Objects, Immediately and After Week Delay: Experiment 1

\begin{tabular}{|c|c|c|c|c|c|c|c|c|c|}
\hline \multirow[b]{3}{*}{ Time of Test } & \multirow[b]{3}{*}{ Condition } & \multicolumn{8}{|c|}{ Condition } \\
\hline & & \multicolumn{4}{|c|}{ Immediate Test } & \multicolumn{4}{|c|}{ Delayed Test } \\
\hline & & $\mathrm{V}-\mathrm{V}$ & $\mathrm{H}-\mathrm{H}$ & $\mathrm{V}-\mathrm{H}$ & $\mathrm{H}-\mathrm{V}$ & $\mathrm{V}-\mathrm{V}$ & $\mathrm{H}-\mathrm{H}$ & $\mathrm{V}-\mathrm{H}$ & $\mathrm{H}-\mathrm{V}$ \\
\hline \multirow[t]{4}{*}{ Immediate } & $\mathrm{V}-\mathrm{V}$ & - & & & & & & & \\
\hline & $\mathrm{H}-\mathrm{H}$ & -.069 & & & & & & & \\
\hline & $\mathrm{V}-\mathrm{H}$ & -.149 & $.481^{* *}$ & & & & & & \\
\hline & $\mathrm{H}-\mathrm{V}$ & -.108 & $.483^{* *}$ & $.408^{* *}$ & & & & & \\
\hline \multirow[t]{4}{*}{ Delay } & $\mathrm{V}-\mathrm{V}$ & $.328^{*}$ & .142 & .280 & .071 & & & & \\
\hline & $\mathrm{H}-\mathrm{H}$ & .205 & .120 & .029 & .126 & .172 & & & \\
\hline & $\mathrm{V}-\mathrm{H}$ & .118 & .305 & .123 & -.052 & .240 & .140 & & \\
\hline & $\mathrm{H}-\mathrm{V}$ & .161 & .247 & .230 & .208 & .002 & .005 & -.228 & - \\
\hline
\end{tabular}

Note-V, visual features; $\mathrm{H}$, haptic features. ${ }^{*} p<.05 . \quad{ }^{* *} p<.01$.

Table 4 shows a hypothetical model that captures the performance ordering obtained in Experiment 1. Each object is composed of visual, haptic, and visual-haptic features. In the numerical example, 75 features are visual, 30 are haptic, and 30 are shared between the modalities. At study, $67 \%$ of all features are encoded into memory. On an immediate test, $80 \%$ of the features extracted from the object match features in memory. Increased recognition accuracy is determined by the total number of matching features (shown at the bottom); the higher the number of matching features, regardless of source (visual, haptic, common), the higher the recognition accuracy. This simple model predicts that $\mathrm{V}-\mathrm{V}>\mathrm{H}-\mathrm{H}>\mathrm{V}-\mathrm{H}=\mathrm{H}-\mathrm{V}$, regardless of the percentage encoded at study or retrieved at test. This ordering was obtained, although the slight $\mathrm{H}-\mathrm{H}$ advantage relative to the two cross-modal conditions failed to reach statistical significance. Forgetting could be based on a reduction of matching features at the time of test.

It is noteworthy that the two cross-modality conditions (i.e., $\mathrm{H}-\mathrm{V}$ and $\mathrm{V}-\mathrm{H}$ ) are predicted to have identical amounts of information available at the time of test even though the $\mathrm{V}-\mathrm{H}$ condition originally encoded more information at the

Table 4

Hypothetical Features (Visual or Haptic) Encoded at Study and Retrieved at Test for Visual and Haptic Objects, Immediate Test

\begin{tabular}{|c|c|c|c|c|c|c|c|}
\hline \multirow{2}{*}{$\begin{array}{l}\text { Feature } \\
\text { Type }\end{array}$} & \multirow{2}{*}{$\begin{array}{l}\text { Population } \\
\text { Features }\end{array}$} & \multicolumn{2}{|c|}{$\begin{array}{l}\text { Encoded at Study } \\
\qquad(67 \%)\end{array}$} & \multicolumn{4}{|c|}{$\begin{array}{c}\text { Retrieved Features That Match Memory } \\
\text { Immediate Test }(80 \%)\end{array}$} \\
\hline & & Visual & Haptic & $\mathrm{V}-\mathrm{V}$ & $\mathrm{H}-\mathrm{H}$ & $\mathrm{V}-\mathrm{H}$ & $\mathrm{H}-\mathrm{V}$ \\
\hline Visual & $\begin{array}{r}\mathrm{V} 1 \\
\mathrm{~V} 2 \\
\bullet \\
\bullet \\
\bullet \\
\mathrm{V} 75\end{array}$ & $\begin{array}{r}\mathrm{V} 1 \\
\mathrm{~V} 2 \\
\bullet \\
\bullet \\
\mathrm{V} 50\end{array}$ & $\begin{array}{l}- \\
- \\
- \\
- \\
-\end{array}$ & $\begin{array}{c}\mathrm{V} 1 \\
\mathrm{~V} 2 \\
\bullet \\
\mathrm{V} 40\end{array}$ & $\begin{array}{l}- \\
- \\
-\end{array}$ & $\begin{array}{l}- \\
- \\
-\end{array}$ & $\begin{array}{l}- \\
- \\
-\end{array}$ \\
\hline $\begin{array}{l}\text { Feature count } \\
\text { Feature matching }\end{array}$ & & 50 & 0 & 40 & 0 & 0 & 0 \\
\hline Visual + Haptic & $\begin{array}{c}\text { VH1 } \\
\text { VH2 } \\
\bullet \\
\bullet \\
\bullet \\
\text { VH30 }\end{array}$ & $\begin{array}{c}\text { VH1 } \\
\text { VH2 } \\
\bullet \\
\bullet \\
\text { VH20 }\end{array}$ & $\begin{array}{c}\text { VH1 } \\
\text { VH2 } \\
\bullet \\
\bullet \\
\text { VH20 }\end{array}$ & $\begin{array}{c}\text { VH1 } \\
\text { VH2 } \\
\bullet \\
\text { VH16 }\end{array}$ & $\begin{array}{c}\text { VH1 } \\
\text { VH2 } \\
\bullet \\
\text { VH16 }\end{array}$ & $\begin{array}{c}\text { VH1 } \\
\text { VH2 } \\
\bullet \\
\text { VH16 }\end{array}$ & $\begin{array}{c}\text { VH1 } \\
\text { VH2 } \\
\bullet \\
\text { VH16 }\end{array}$ \\
\hline $\begin{array}{l}\text { Feature count } \\
\text { Feature matching }\end{array}$ & 20 & 20 & & 16 & 16 & 16 & 16 \\
\hline Haptic & $\begin{array}{r}\mathrm{H} 1 \\
\mathrm{H} 2 \\
\bullet \\
\bullet \\
\bullet \\
\mathrm{H} 30\end{array}$ & $\begin{array}{l}- \\
- \\
- \\
- \\
- \\
-\end{array}$ & $\begin{array}{c}\mathrm{H} 1 \\
\mathrm{H} 2 \\
\bullet \\
\bullet \\
\mathrm{H} 20\end{array}$ & $\begin{array}{l}- \\
- \\
- \\
- \\
- \\
-\end{array}$ & $\begin{array}{c}\mathrm{H} 1 \\
\mathrm{H} 2 \\
\bullet \\
\mathrm{H} 16\end{array}$ & $\begin{array}{l}- \\
- \\
- \\
-\end{array}$ & $\begin{array}{l}- \\
- \\
- \\
-\end{array}$ \\
\hline $\begin{array}{l}\text { Feature count } \\
\text { Feature matching }\end{array}$ & 0 & 20 & & 0 & 16 & 0 & 0 \\
\hline $\begin{array}{l}\text { Total count } \\
\text { Total matching }\end{array}$ & 70 & 40 & & 56 & 32 & 16 & 16 \\
\hline
\end{tabular}

Note-V, visual features; H, haptic features. V-V, H-H, V-H, and H-V, study-test conditions. For further explanation, see text. 
time of study. The H-H condition would have a slight advantage over the two cross-modality conditions, because idiosyncratic information unique to the haptic modality is fully represented only in the $\mathrm{H}-\mathrm{H}$ condition.

A further test of this model, using a successive cuing paradigm, formed the basis for Experiment 2 . If substantially more information is encoded by the visual modality, much of which is unique and not shared by the haptic modality, then a cuing advantage should exist for the visual modality. That is, if an event is encoded both visually and haptically, then a subject's judgment regarding that event should be bolstered if a haptic test is followed by a visual one. In contrast, the reduced information available to the haptic modality should produce a smaller cuing benefit when a visual test is followed by a haptic one. Furthermore, the visual advantage might be expected to be more prominent after a week's delay, given that the haptic information appeared to be heavily degraded after such a delay.

\section{EXPERIMENT 2}

\section{Method}

Subjects. The subjects were 40 Arizona State University students ( 25 male and 15 female), half in the immediate condition and half in the delayed. None of the subjects had participated in Experiment 1. All subjects had normal or corrected-to-normal vision, and none presented somatosensory deficits.

Materials and Apparatus. A different apparatus was used in Experiment 2 . An opaque curtain, $3 \mathrm{ft}$ tall and $2 \mathrm{ft}$ wide, was suspended over a table to allow presentation of the objects both haptically (with the curtain closed) and visually (by opening the curtain). The subject was seated with both arms on the table. For all subjects, the study phase involved simultaneous haptic and visual inspection. The same objects from Experiment 1 were used in order to ensure comparability. During the visual portions of the test phase, objects were placed on a turntable to allow subjects to view the objects without touching them. The curtain was closed during the haptic test so that subjects could explore with both hands while not seeing the object.

Procedure. Each of the 40 objects from the A or B list was handed to the subject for $5 \mathrm{sec}$ of visual and haptic inspection, followed by a recognition test either immediately or after a week's delay. In the test phase, 10 studied and 10 foil objects were selected randomly and tested in the order visual-followed-by-haptic $(\mathrm{V}-\mathrm{H})$, with the remaining 20 objects or foils tested in the opposite sequence $(\mathrm{H}-\mathrm{V})$. Half the subjects received the order $\mathrm{V}-\mathrm{H}$ followed by $\mathrm{H}-\mathrm{V}$, and the other half received the test in the opposite order.

During the recognition test, subjects were asked to identify the object as old or new, following instructions similar to those for Experiment 1 . The recognition test was self-paced, with most subjects taking less than $5 \mathrm{sec}$ to reach their judgment. Following the judgment, the object was presented again, in the other modality, and the subject was asked to make a second judgment. The instructions made it clear that the subject was free to change his or her initial judgment.

\section{Results}

Performance on Test 1 . Table 5 shows the hit, false alarm, and signal detection values of $d^{\prime}$ and criterion on the initial test, as a function of test modality (visual, haptic) and time of test (immediate, week delay). A signal detection analysis revealed that $d^{\prime}$ was again greater for the visual than for the haptic modality $[F(1,38)=46.38$, $\left.M S_{\mathrm{e}}=0.31, p<.001, \eta^{2}=.55\right]$. The effect of delay was significant $\left[F(1,38)=46.81, M S_{\mathrm{e}}=0.54, p<.001, \eta^{2}=\right.$ $.55]$, but the test modality $\times$ delay interaction was not
$(F<1) .^{2}$ As was the case in Experiment 1, the haptic modality produced a higher false alarm rate, and the criterion placement was more liberally positioned than for the visual test.

Performance on Test 2. Figure 2 shows the likelihood of a correct recognition judgment on the second test, given an error on the initial test.

On the immediate test, subjects corrected an initial haptic error $70 \%$ of the time when visual inspection of the object was then provided; after 1 week, this correction rate dropped to $40 \%$. In contrast, subjects corrected an initial visual error nearly $30 \%$ of the time when haptic inspection occurred; on the delayed test, this rate dropped nearly to zero. The visual cue advantage did not arise from subjects' missing only the most difficult objects; the mean visual recognition accuracy of objects missed visually that were successfully corrected by the haptic test (.850) did not differ from those missed visually but not corrected by the haptic test (.877). Interestingly, subjects rarely changed a correct initial judgment to an incorrect one with the second test, with fewer than five such occurrences total.

\section{GENERAL DISCUSSION}

Haptic information, gleaned from a brief inspection, survives a week's delay, whether tested in the same or in an alternative modality. Previous studies have shown that a brief inspection of a picture is retained at better than chance levels after 3 months with thematically similar foils (Homa \& Viera, 1988) and up to a year with random foils (Nickerson, 1968). The present study demonstrates that haptic exploration can leave an enduring trace as well. Furthermore, subjects who explored the objects haptically must have retained more than the name of the object at the time of study, since foils belonged to the same basic level category and shared the same name. Presumably, subjects encoded and retained either the felt, haptic sensations or particular features of the studied object in such a way that it could be discriminated from a categorically similar foil. Nonetheless, after a week delay, the level of haptic recognition was far less than its visual counterpart. Whether haptic memory would survive delays longer than 1 week is unclear.

When objects were studied both haptically and visually (Experiment 2), subjects often corrected a later recognition judgment when allowed to explore the object with the alternative modality, but again, the visual modality outperformed the haptic. The haptic modality also corrected the visual modality but at reduced levels, with this

Table 5

Performance Measures for Recognition Test 1: Experiment 2

\begin{tabular}{ccccccc}
\hline \multicolumn{1}{c}{ Time } & Test & Acc & $P(\mathrm{H})$ & $P(\mathrm{FA})$ & $d^{\prime}$ & $c$ \\
\hline Immediate & Visual & .920 & .960 & .120 & 2.76 & 1.20 \\
& Haptic & .795 & .970 & .380 & 1.90 & 0.32 \\
Mean & & .858 & .965 & .250 & 2.33 & 0.76 \\
Week & Visual & .740 & .915 & .435 & 1.63 & 0.19 \\
& Haptic & .622 & .855 & .610 & 0.79 & -0.38 \\
Mean & & .681 & .885 & .522 & 1.21 & -0.10 \\
\hline
\end{tabular}

Note-Acc, accuracy; H, hits; FA, false alarms; $c$, criterion placement. 


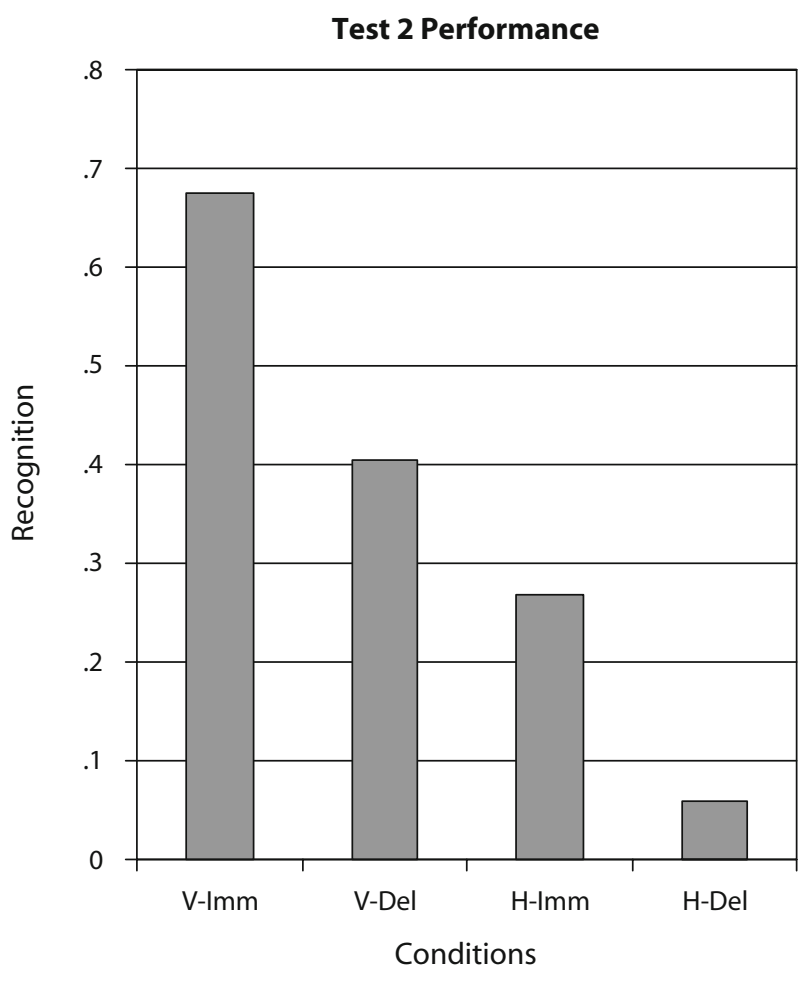

Figure 2. Likelihood of correct recognition on Test 2, conditional upon an error on Test 1 , as a function of Test $\mathbf{2}$ modality (visual, haptic), and time of test (immediate, 1-week delay), Experiment 2.

tendency virtually vanishing after a 1-week delay. Since haptic information survives a week delay (Experiment 1), two possibilities exist: (1) The unique portion provided by haptic exploration had faded so much that further contribution to the visual modality was minimal; or (2) subjects have a decisional bias to trust their visual modality more than the haptic one, even when their recognition judgment is in error.

Left unanswered is how object encodings from different modalities are represented in immediate and in delayed memory. There is no dispute that regions such as the occipito-temporal cortex are activated by both touch and vision (Amedi, Malach, Hendler, Peled, \& Zohary, 2001) and that visual and haptic cross-modality priming activates overlapping areas in the middle and lateral occipital cortex (James et al., 2002). Intuitively, our concepts seem modality free. Nevertheless, object recognition could be determined by recruiting and combining properties from encodings that have maintained their distinct modality status. The finding of similar retention loss for the haptic, visual, and crossmodality manipulations suggests that this information may exist in a modality-free format. Regardless, we know little about activated areas that are shared or distinct in a delayed memory paradigm, as in the present study.

Finally, we are uncertain whether the present results would generalize to other types of objects. We intentionally selected a wide range of objects from diverse categories, but we cannot dismiss the possibility that properties unique to the haptic modality might be underrepresented in our sample. For example, haptic memory might have fared better had the foils differed more dramatically along dimensions such as weight or texture. Subsequent experiments that explore more systematic variations of haptic dimensions are needed, as are studies that address whether memory for an event can shed its modality tag at input to become a modality-free memory.

\section{AUTHOR NOTE}

We thank Steven Goldinger and Christopher Willie for reading an earlier version of the manuscript. Requests for reprints should be sent to D. Homa, Department of Psychology, Arizona State University, Tempe, AZ 85287 (e-mail: donhoma@asu.edu).

\section{REFERENCES}

Amedi, A., Malach, R., Hendler, T., Peled, S., \& Zohary, E. (2001). Visuo-haptic object-related activation in the ventral visual pathway. Nature Neuroscience, 4, 324-330.

Bushnell, E. W., \& BAXT, C. (1999). Children's haptic and crossmodal recognition with familiar and unfamiliar objects. Journal of Experimental Psychology: Human Perception \& Performance, 25, 1867-1881.

Easton, R. D., Srinivas, K., \& Greene, A. J. (1997). Do vision and haptics share common representations? Implicit and explicit memory within and between modalities. Journal of Experimental Psychology: Learning, Memory, \& Cognition, 23, 153-163.

ERnst, M. O., \& Banks, M. S. (2002). Humans integrate visual and haptic information in a statistically optimal fashion. Nature, 415, 429-433.

Green, D. M., \& Swets, J. A. (1966). Signal detection theory and psychophysics. New York: Wiley.

Homa, D., \& Viera, C. (1988). Long-term memory for pictures under conditions of thematically related foils. Memory \& Cognition, 16, 411-421.

James, T. W., Humphrey, G. K., Gati, J. S., Servos, P., Menon, R. S., \& Goodale, M. A. (2002). Haptic study of three-dimensional objects activates extrastriate visual areas. Neuropsychologia, 40, 1706-1714.

Klatzky, R. L., Lederman, S. J., \& Metzger, V. A. (1985). Identifying objects by touch: An “expert system." Perception \& Psychophysics, 37, 299-302.

Mather, G. (2006). Foundations of perception. Hove, U.K.: Psychology Press, Erlbaum.

Millar, S., \& Al-Attar, Z. (2005). What aspects of vision facilitate haptic processing? Brain \& Cognition, 59, 258-268.

Newell, F. N. (2004). Cross-modal object recognition. In G. A. Calvert, C. Spence, \& B. E. Stein (Eds.), The handbook of multisensory processes (pp. 123-139). Cambridge, MA: MIT Press.

NiCKERSON, R. S. (1968). On long-term recognition memory for pictorial material. Psychonomic Science, 11, 58.

Norman, J. F., Norman, H. F., Clayton, A. M., Lianekhammy, J., \& ZIELKE, G. (2004). The visual and haptic perception of natural object shape. Perception \& Psychophysics, 66, 342-351.

Schooler, L. J., \& SHIFFrin, R. M. (2005). Efficiently measuring recognition performance with sparse data. Behavior Research Methods, 37, 3-10.

Shimojo, S., \& Shams, L. (2001). Sensory modalities are not separate modalities: Plasticity and interactions. Current Opinion in Neurobiology, 11, 505-509.

Stanislaw, H., \& Todorov, N. (1999). Calculation of signal detection theory measures. Behavior Research Methods, Instruments, \& Computers, 31, 137-149.

\section{NOTES}

1. Each subject's hit and false alarm rates were converted to $d^{\prime}$ and a criterion $(c)$, with hit rates of 1.00 converted to .95 and false alarm rates of 0 to .05 , a correction recommended by Stanislaw and Todorov (1999). This correction has the potential to bias the sensitivity measure 
$\left(d^{\prime}\right)$, a concern also noted by one of the reviewers. Therefore, we also converted recognition performance for sparse data to the gamma statistic (Schooler \& Shiffrin, 2005). This analysis leaves unchanged the outcomes reported for the $d^{\prime}$ analysis. However, the condition $\times$ delay interaction approached significance $\left[F(3,76)=2.28, M S_{\mathrm{e}}=0.095, p=\right.$ .09 ], with the $\mathrm{V}-\mathrm{V}$ condition showing slightly less forgetting than the other three conditions. Therefore, the conclusion that visual and haptic information decayed at the same rate across the week delay should be treated with caution.

2. An analysis based on percent correct, in which hits and correct rejections are combined, yielded the same conclusions as $d^{\prime}$ in both Experiments 1 and 2 .

APPENDIX

Objects and the Two Variations Used in Experiments 1 and 2

\begin{tabular}{|c|c|c|}
\hline Object & Version 1 & Version 2 \\
\hline Toy car & red sedan & white coupe \\
\hline Stapler & black square tipped & black round tipped \\
\hline Stem vase & clear with fluted rim & bluish with flat rim \\
\hline Square sponge & red and yellow porous & green plastic wired \\
\hline Plastic toy & blue pliers & red needle-nose pliers \\
\hline Flashlight & stainless steel & yellow plastic \\
\hline Paper clasp & $1 / 2$ inch small & $3 / 4$ inch large \\
\hline Flower pot figurine & turtle with green hat & squirrel with brown hat \\
\hline Ball & soccer ball & volleyball \\
\hline Aluminum can & carrots with pull top & tomatoes with flat top \\
\hline Wooden spoon & two slots & one slot \\
\hline Bottle cap & blue smooth & clear with serrated edges \\
\hline Toy bear (3-in.) & girl bear with dress & boy bear with overalls \\
\hline Hair brush & rounded handle & square handle \\
\hline Plastic box & disc-drive container & birth control packet container \\
\hline Fluted vase & round foot & polygon foot \\
\hline Measuring cup & green triangular & yellow round \\
\hline Pen & black with plastic tip & black with metal tip \\
\hline Stick & wooden paint stick & plastic ruler \\
\hline Plastic toy gorilla & open-jawed & posed on rock \\
\hline Cardboard box & green square & blue rectangular \\
\hline Pill bottle & latched safety lid & single push down safety lid \\
\hline Cosmetic bag & pink zippered & brown zippered with ridge pattern \\
\hline Battery & size D & size $\mathrm{C}$ \\
\hline Plastic fruit & orange & lemon \\
\hline Candleholder & rounded cup with red glass & squared cup with purple glass \\
\hline Picture frame & $\mathrm{red} /$ white/blue with squares & $\mathrm{red} /$ white/blue with circles \\
\hline Nail polish bottle & white with lid insignia & pink with flat lid \\
\hline Small ball & heavy yellow rubber & soft pink rubber \\
\hline Plastic fast food cup & clear plastic & opaque plastic \\
\hline Foam shape & pink heart & green train \\
\hline Measuring spoon & tablespoon & teaspoon \\
\hline Shoelaces & black dress lace & white sport lace \\
\hline Frisbee & orange with handles & blue with no handles \\
\hline Plastic toy animal & cheetah & giraffe \\
\hline Powder compact & yellow with square label & black with no label \\
\hline Coffee cup & white with raised flowers & purple with raised lines \\
\hline Calculator & grey, longer & white, with slip-on cover \\
\hline Plastic bowl & "Tupperware" white lid & blue rimmed lid \\
\hline Wrench & close ended & open ended \\
\hline
\end{tabular}

(Manuscript received December 21, 2006;

revision accepted for publication November 9, 2007.) 